\title{
Proceeding
}

10th INSHS International Christmas Sport Scientific Conference, 4-5 December 2015. International Network of Sport and Health

Science. Szombathely, Hungary

\section{Change in body composition of female junior volleyball players}

JINDŘICH PAVLÍK ${ }^{1}$, TOMÁŠ VESPALEC ${ }^{2}$, TOMÁŠ ZEMAN ${ }^{3}$

${ }^{1}$ Department of Sports, Masaryk University, Brno, Czech Republic

2 Department of Kinesiology, Masaryk University, Brno, Czech Republic

${ }^{3}$ Department of Biochemistry, Laboratory of Neurobiology and Molecular Psychiatry, Masaryk University, Brno, Czech Republic

\begin{abstract}
The purpose of our study is to monitor and analyze the composition of selected body masses of female $v$ junior volleyball players. The data were obtained from 18 players, aged 14 to 19 years, of the Královo Pole volleyball club in Brno, Czech Republic (VV KP Brno), between 1 August 2014 and 20 December 2014. Body composition was measured by Inbody 230 - Biospace using the bioimpedance measurement method. We obtained the following data from measurement: BMI (Body Mass Index), PBF (Percentage Body Fat), body mass, muscle and fat mass of both upper and lower limbs and the trunk. Mann-Whitney $U$ test is used to compare differences between the values obtained before the preseason preparation, after the preseason preparation and after three months of the season. All statistical computations were performed using $R$ software ( $R$ Core Team 2013). Comparing the results after the preliminary part we diagnosed a significant difference $(p<0.05)$ increase of percentage of total fat mass $(p=0.0266)$. After the preliminary part of the season significant difference describing increase of body mass $(p=0.0462)$ was found, together with increase of body fat in left upper ( $p=0.0313)$, right upper $(p=0.0429)$ limb and with increase of trunk mass $(p=0.0379)$. The study revealed interesting information about a change of the body mass and body fat percentage of volleyball players of VK KP Brno during the regular season. The findings from the preseason preparation confirmed the expected change, i.e. that the muscle mass increases while the body mass and body fat percentage decrease. Key words: VOLLEYBALL, IN-BODY, BIOIMPEDANCE.
\end{abstract}

Corresponding author. Masaryk University, Faculty of Sports Studies, Department of Sports, Kamenice 5, 62500 Brno, Czech Republic

E-mail: pavlikj@fsps.muni.cz

10th INSHS International Christmas Sport Scientific Conference, 4-5 December 2015. International Network of Sport and Health Science. Szombathely, Hungary.

JOURNAL OF HUMAN SPORT \& EXERCISE ISSN 1988-5202

(c) Faculty of Education. University of Alicante

doi:10.14198/jhse.2016.11.Proc1.09

VOLUME 11| Proc1 | 2016 | S195 


\section{INTRODUCTION}

Monitoring of sports performance and its analysis continues to be a vividly discussed issue. According to Buchtel (2009), there are qualitative and quantitative aspects of volleyball player's performance. Player's performance does not require only tactical, technical and mental training, but also physical exercise, which is crucial to their performance. After consulting coaches of female junior and senior volleyball players, we observed that physical training and subsequent performance has increasingly been affected by other objectively measurable factors.

In many cases, in particular with girls, it is of utmost importance to monitor other somatic factors affecting their skills. Such factors are very specific and may be different for different players. One of such factors is body composition. Body composition monitoring of elite volleyball players was analyzed in several studies of Malý et al. (2011); Malý et al. (2010). Tsunawake et al. (2003) compared body composition of junior basketball and volleyball players and their physical fitness. Andreoli et al. (2003) analyzed the effects of different sports on body cell mass in highly trained athletes. However, most of the studies took measurements of the given sample only once. In our study, we intend to use repeated measurements throughout the season, to record changes of the body composition in order to provide vital objective information for the training process and matches. A similar issue was looked at by Kavazis (2014) who compared changes in body composition and stress factors in NCAA volleyball players during the season.

The objective of our study is to monitor and analyze the composition of selected body components in junior female volleyball players in the Czech Republic. Following consultations with coaches of junior teams, we would like to verify their empiric observations describing variable body composition, in particular body mass, during the preseason and regular season.

\section{MATERIAL AND METHODS}

Testing was performed in the Sports Centre of VK KP Brno. It was performed six times in total during the entire season 2014/2015, always once a month in the beginning of a weekly training programme. Measurements were taken on the same day, thirty minutes before the first training unit. Before measurements, all players had a day off, without any exercise or match. At the beginning of the whole measurement cycle, the players were informed about the crucial factors (drinking and eating patterns etc.) which may have an impact on the measurement. The players were measured barefoot, wearing a T-shirt and shorts.

\section{Participants}

The sample includes 18 junior female volleyball players of VK KP Brno, aged 14-19 let. All players are members of teams in the highest junior league.

\section{Measures}

Body composition was measured on In-body 230 - Biospace using the bioimpedance measurement method. We obtained the following components from measurements: BMI (Body Mass Index), PBF (Percentage Body Fat), body mass, muscle and fat mass of both upper and lower limbs and the trunk.

\section{Data Analyses}


For data evaluation, we used all six measurements in the first phase; in the second phase, we used only measurements taken before the preseason preparation, after the preseason preparation and at the end of the autumn season processed from players participating in all measurements.

Mann-Whitney $U$ test is used to compare differences between the values obtained before the preseason preparation, after the preseason preparation and after three months of the season. All statistical computations were performed using $R$ software (R Core Team 2013). Significance was established at $p<0.05$. Data are reported as mean \pm SD.

\section{RESULTS}

During the preseason preparation (31 calendar days), the average body mass of the players decreased, while the body fat percentage decreased in all somatic components and the muscle mass percentage increased.

During the performance part (95 days) we observed ongoing trend of body mass increase. However, during this interval trend connected with increase of body fat mass in all measured body parts was described.

Specifically, after the preliminary part we diagnosed a significant difference $(p<0.05)$ increase of percentage of total fat mass $(p=0.0266)$ (Fig. 1). After the preliminary part of the season significant difference describing increase of body mass ( $p=0.0462$ ) (Fig. 2) was found, together with increase of body fat in left upper $(p=0.0313)$ (Fig. 3), right upper $(p=0.0429)$ (Fig. 4) limb and with increase of trunk mass $(p=0.0379)$ (Fig. 5).

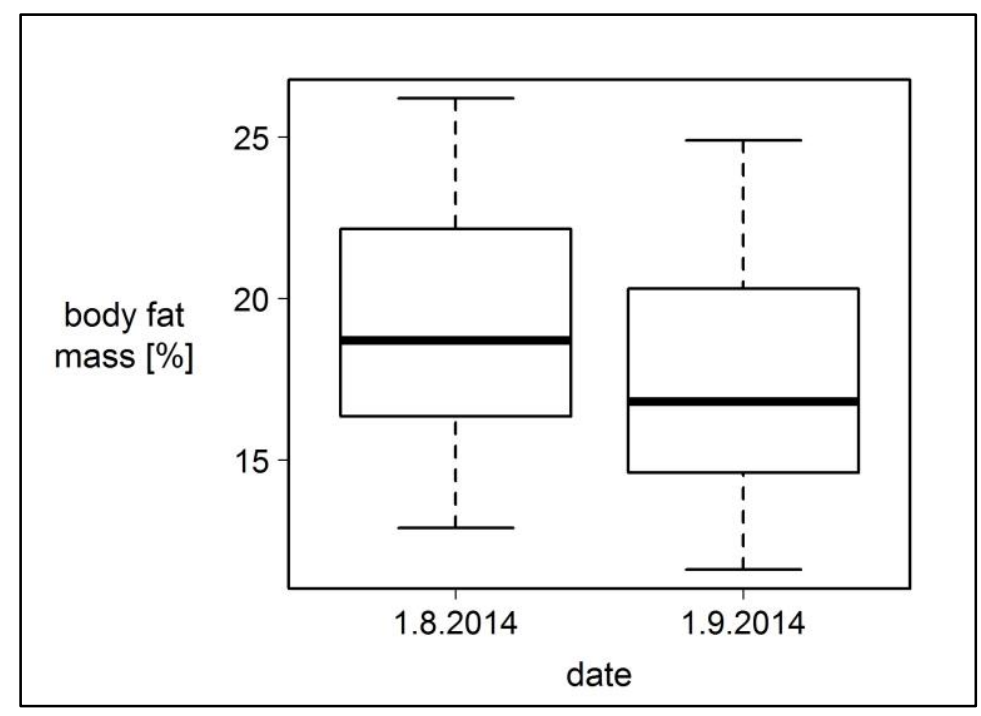

Figure 1. Increase of body fat mass 


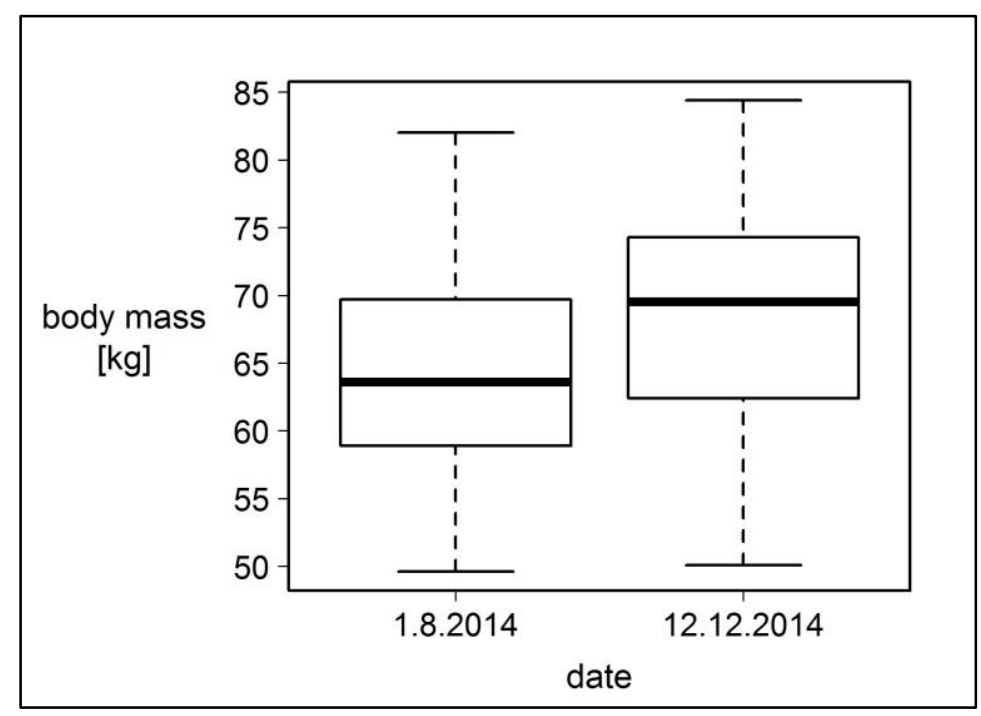

Figure 2. Increase of body mass

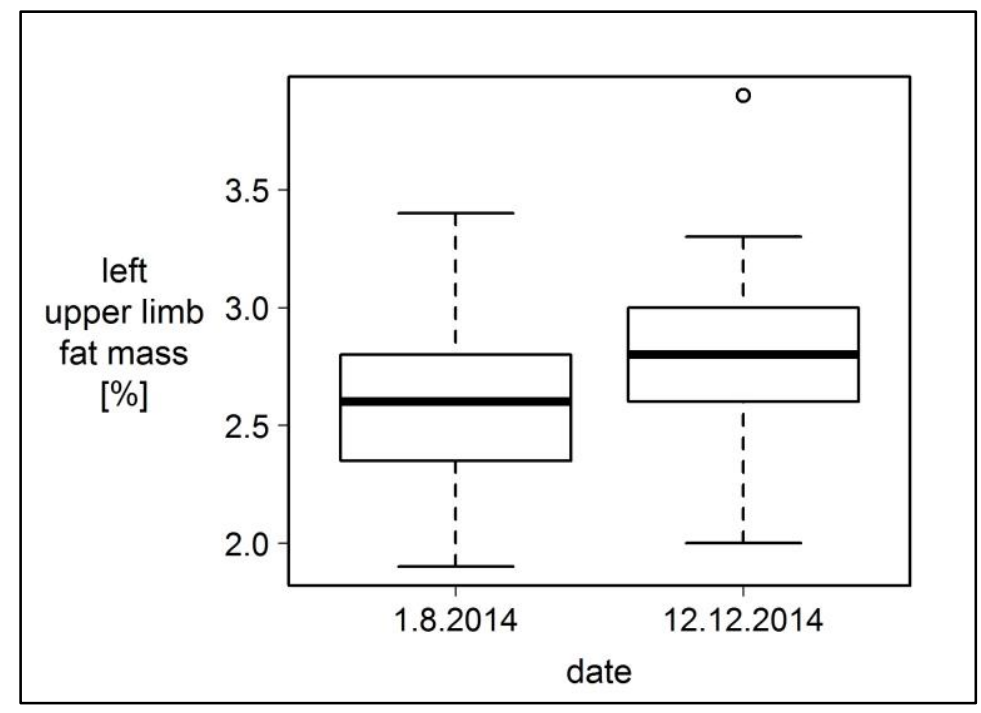

Figure 3. Increase of body fat in left upper limb 


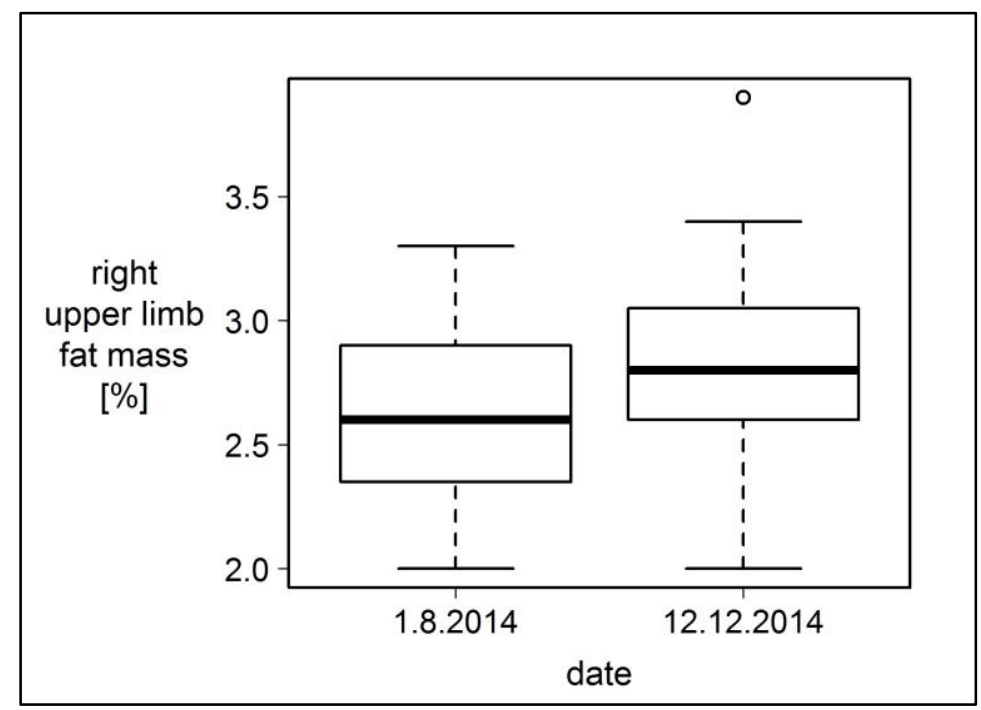

Figure 4. Increase of body fat in right upper limb

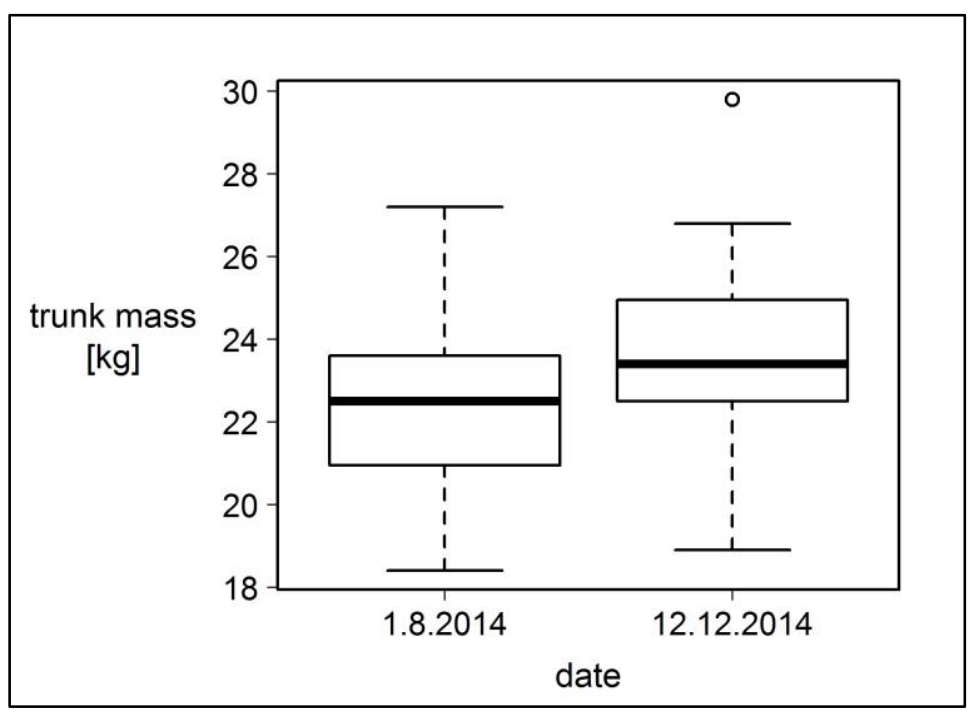

Figure 5. Increase of trunk mass

\section{DISCUSSION}

We expected that after the preseason preparation at the beginning of the season, there would be a decrease in the body mass and body fat percentage of all players. We also anticipated that due to prevailing power and athletic nature of training, there would be an increase in the muscle mass. Furthermore, we expected that the players would retain the muscle mass percentage for the entire regular season.

The results confirmed the empirical presumption that after the preseason preparation, in the first months of the season, there was a decrease in the body mass - the body fat percentage decreased and the muscle mass percentage increased. It was surprising to find out that during the autumn section of the regular season, we observed an increase in the body fat percentage in all measured parts of the body. Such changes 
manifested in an increase in the body mass in $\mathrm{kg}$ during the regular season, while the muscle mass of most of the players stagnated or reduced during the regular season.

This trend is, to a certain extent, attributable to poor eating habits of the players caused in particular by lack of time to eat regularly during the day (school, number of training units). Another factor may be lower exercise intensity during the regular season compared with the preseason preparation. During this period, the weekly training programme consists mainly of volleyball trainings. These are, however, only speculations, as the causality was not examined in our study.

Following the results of our study, we would recommend monitoring eating patterns of the players and their daily intake. The training process should include exercise of higher intensity, such as muscle-building and compensatory exercises. Aerobic exercise should become an integral part of the weekly training programme.

\section{CONCLUSIONS}

The objective of our study was to monitor and analyze the composition of selected body masses of female junior volleyball players. The results suggest that their body mass decreases and the fat mass turns into the muscle mass in the preseason preparation. However, during the regular season the sample of the volleyball players showed an undesired increase in the body mass and body fat percentage. We believe this is attributable to poor eating patterns of the players. The results of our study could be used by coaches as objective information for the preparation of training programmes throughout the entire season.

\section{REFERENCES}

1. Andreoli, A., Melchiorri, G., Brozzi, M., Di Marco, A., Volpe, S. L., Garofano, P., \& De Lorenzo, A. (2003). Effect of different sports on body cell mass in highly trained athletes. Acta Diabetologica, 40, 122-125.

2. Kavazis, A. N., \& Wadsworth, D. D. (2014). Changes in body composition and perceived stress scale10 in in National Collegiate Athletic Association Division I female volleyball players. Archives of Exercise Health and Disease, 4(3), 320-325. doi: 10.5628/aehd.v4i2.173

3. Malý, T., Zahálka, F., \& Malá, L. (2010). Body composition profi le of elite women volleyball players. International Journal of Volleyball Research, 10(1), 14-19.

4. Malý, T., Malá, L., Zahálka, F., Baláš, J., \& Čada, M. (2011). Comparison of Body Composition between Two Elite Women's Volleyball Teams. Acta Universitatis Palackianae Olomucensis Gymnica, 41(1).

5. Tsunawake, N., Tahara, Y., Moji, K., Muraki, S., Minowa, K., \& Yukawa, K. (2003). Body Composition and Physical Fitness of Female Volleyball and Basketball Players of the Japan Interhigh School Championship Teams. Journal of Physiological Anthropology and Applied Human Science. doi:10.2114/jpa.22.195

6. Vlachá, T. (2011). Možnosti ovlivnění nadváhy a zdatnosti u hráček volejbalu. (Unpublished masters dissertation). Charles University, Faculty of Sports, Praha, Czech Republic. 